\title{
Imaging assessment of children presenting with suspected or known juvenile idiopathic arthritis: ESSR-ESPR points to consider
}

\author{
Robert Hemke ${ }^{1}$ - Nele Herregods ${ }^{2}$. Jacob L. Jaremko ${ }^{3}$. Gunnar Åström ${ }^{4}$ • Derk Avenarius ${ }^{5}$ • Fabio Becce ${ }^{6}$. \\ Dennis K. Bielecki ${ }^{7}$. Mikael Boesen ${ }^{8}$. Danoob Dalili ${ }^{9}$. Chiara Giraudo ${ }^{10} \cdot$ Kay-Geert Hermann ${ }^{11}$ • Paul Humphries ${ }^{12}$. \\ Amanda Isaac ${ }^{13}$ - Anne Grethe Jurik ${ }^{14}$. Andrea S. Klauser ${ }^{15}$. Ola Kvist ${ }^{16}$ • Frederiek Laloo $^{2}$. Mario Maas ${ }^{1}$. \\ Adam Mester ${ }^{17}$. Edwin Oei ${ }^{18}$. Amaka C. Offiah ${ }^{19} \cdot$ Patrick Omoumi $^{6}$. Olympia Papakonstantinou ${ }^{20}$. \\ Athena Plagou $^{21}$ - Susan Shelmerdine ${ }^{12}$ - Paolo Simoni ${ }^{22} \cdot$ Iwona Sudoł-Szopińska ${ }^{23}$ - Laura Tanturri de Horatio ${ }^{24}$. \\ James Teh $^{25} \cdot$ Lennart Jans ${ }^{2} \cdot$ Karen Rosendahl ${ }^{5}$
}

Received: 20 November 2019 / Revised: 8 February 2020 / Accepted: 12 March 2020 / Published online: 12 May 2020

(C) The Author(s) 2020

\begin{abstract}
Juvenile idiopathic arthritis (JIA) is the most common paediatric rheumatic disease. It represents a group of heterogenous inflammatory disorders with unknown origin and is a diagnosis of exclusion in which imaging plays an important role. JIA is defined as arthritis of one or more joints that begins before the age of 16 years, persists for more than 6 weeks and is of unknown aetiology and pathophysiology. The clinical goal is early suppression of inflammation to prevent irreversible joint damage which has shifted the emphasis from detecting established joint damage to proactively detecting inflammatory change. This drives the need for imaging techniques that are more sensitive than conventional radiography in the evaluation of inflammatory processes as well as early osteochondral change. Physical examination has limited reliability, even if performed by an experienced clinician, emphasising the importance of imaging to aid in clinical decision-making. On behalf of the European Society of Musculoskeletal Radiology (ESSR) arthritis subcommittee and the European Society of Paediatric Radiology (ESPR) musculoskeletal imaging taskforce, based on literature review and/or expert opinion, we discuss paediatric-specific imaging characteristics of the most commonly involved, in literature best documented and clinically important joints in JIA, namely the temporomandibular joints (TMJs), spine, sacroiliac (SI) joints, wrists, hips and knees, followed by a clinically applicable point to consider for each joint. We will also touch upon controversies in the current literature that remain to be resolved with ongoing research.

Key Points

- Juvenile idiopathic arthritis (JIA) is the most common chronic paediatric rheumatic disease and, in JIA imaging, is increasingly important to aid in clinical decision-making.

- Conventional radiographs have a lower sensitivity and specificity for detection of disease activity and early destructive change, as compared to MRI or ultrasound. Nonetheless, radiography remains important, particularly in narrowing the differential diagnosis and evaluating growth disturbances.

- Mainly in peripheral joints, ultrasound can be helpful for assessment of inflammation and guiding joint injections. In JIA, MRI is the most validated technique. MRI should be considered as the modality of choice to assess the axial skeleton or where the clinical presentation overlaps with JIA.
\end{abstract}

Electronic supplementary material The online version of this article (https://doi.org/10.1007/s00330-020-06807-8) contains supplementary material, which is available to authorized users.

Robert Hemke

r.hemke@amsterdamumc.nl

Extended author information available on the last page of the article 
Keywords Diagnostic imaging - Juvenile idiopathic arthritis - Magnetic resonance imaging · Conventional radiography . Ultrasound computed tomography

\begin{tabular}{|c|c|}
\hline bbreviatıor & \\
\hline ASAS & $\begin{array}{l}\text { Assessment in Spondyloarthritis International } \\
\text { Society }\end{array}$ \\
\hline CARRA & $\begin{array}{l}\text { Childhood Arthritis and Rheumatology } \\
\text { Research Alliance }\end{array}$ \\
\hline CT & Computed tomography \\
\hline ERA & Enthesitis-related arthritis \\
\hline ESPR & European Society of Paediatric Radiology \\
\hline ESSR & $\begin{array}{l}\text { European Society of Musculoskeletal } \\
\text { Radiology }\end{array}$ \\
\hline JAMRIS & Juvenile Arthritis MRI Scoring \\
\hline JIA & Juvenile idiopathic arthritis \\
\hline MRI & Magnetic resonance imaging \\
\hline OMERACT & $\begin{array}{l}\text { Outcome Measures in Rheumatology Clinical } \\
\text { Trials }\end{array}$ \\
\hline RAMRIS & Rheumatoid Arthritis MRI Scoring \\
\hline SI & Sacroiliac \\
\hline $\mathrm{SpA}$ & Spondyloarthritis \\
\hline SPARCC & $\begin{array}{l}\text { Spondyloarthritis Research Consortium of } \\
\text { Canada }\end{array}$ \\
\hline TMJ & Temporomandibular joint \\
\hline & Ultrasound \\
\hline
\end{tabular}

\section{Paediatric-specific items per joint}

\section{Axial joints}

\section{Temporomandibular joints}

Temporomandibular joint (TMJ) involvement is common in children with juvenile idiopathic arthritis (JIA), and it is often present early in the disease [1]. It has been implicated in 40$87 \%$ of JIA patients on magnetic resonance imaging (MRI) [2-6]. Similar to the involvement of other axial joints, TMJ involvement in JIA is difficult to detect clinically [7].

The main growth centre of the mandible is located in the condyle, and mandibular growth is therefore vulnerable to arthritic changes [8]. Early detection and treatment of TMJ arthritis is important to preserve mobility and to prevent growth abnormalities and deformities which have been found to be associated with impaired health-related quality of life [9]. Conventional radiography and cone beam computed tomography (CT) are used to detect condylar bony abnormalities (Fig. 1). Compared to conventional radiography, CT and cone beam CT avoid difficulties of superimposition and offer unsurpassed resolution of cortical surfaces, but soft tissue changes such as those related to the disc and joint capsule as well as bone marrow oedema cannot accurately be assessed [9, 10].
Ultrasound (US) could potentially detect both osteochondral and soft tissue changes. It is, however, not practical for the assessment of axial joint arthritis. US was found to moderately correlate with contrast-enhanced MRI in the detection of TMJ involvement in children with JIA [11, 12]. The usefulness of ultrasound for the TMJ is limited due to the complex nature of this joint [13]. There are no accepted USbased normative values for synovial thickness (Table 1), and a valid US scoring system for the TMJ is lacking (Table 2).

MRI is the modality of choice for the assessment of TMJ arthritis as it can detect acute and early inflammatory changes consisting of joint effusion, synovial enhancement/thickening and bone marrow oedema, as well as chronic changes including erosions, osseous deformity, new bone formation and disc abnormalities [14]. Small dots or lines of high signal intensity on T2-weighted sequences within the joint recesses are considered physiological joint fluid [15]. Synovial thickness is difficult to measure due to rapid diffusion of contrast to the synovial fluid, but comparing post-contrast T1-weighted fatsaturated images to pre-contrast T2-weighted fat-saturated images which demonstrates the extent of joint effusion can be helpful [9, 16]. Figure 2 depicts an example of active TMJ arthritis on MRI. For optimal evaluation of the TMJ, an MRI protocol preferably includes sequences with open and closed mouth. For evaluating the disc position and function in relation to the condyle, open-mouth views are valuable when compared with closed-mouth views [17]. The condyle morphology is best evaluated with a closed-mouth view [17]. Some MRI scoring systems for TMJ evaluation in JIA are available (Table 2). An example of an MRI protocol for the TMJ in JIA is given in Supplementary File 1.

Point to consider TMJ MRI could be performed in patients suspected clinically of TMJ involvement, with fluid-sensitive, closed and open mouth, and potentially, post-gadolinium sequences.

Rationale Detection of TMJ involvement allows earlier treatment which may reduce growth deformity and TMJ dysfunction. Closed and open mouth imaging may demonstrate alternative mechanical aetiologies for findings and can help in understanding the functional limitations of the joint, as well as the impact of JIA on the TMJ disc.

Controversies/future developments (a) Given that TMJ arthropathy is often clinically silent, should patients with JIA have screening TMJ MRI? (b) Is gadolinium necessary to depict inflammation, or does fluid-sensitive imaging suffice? 


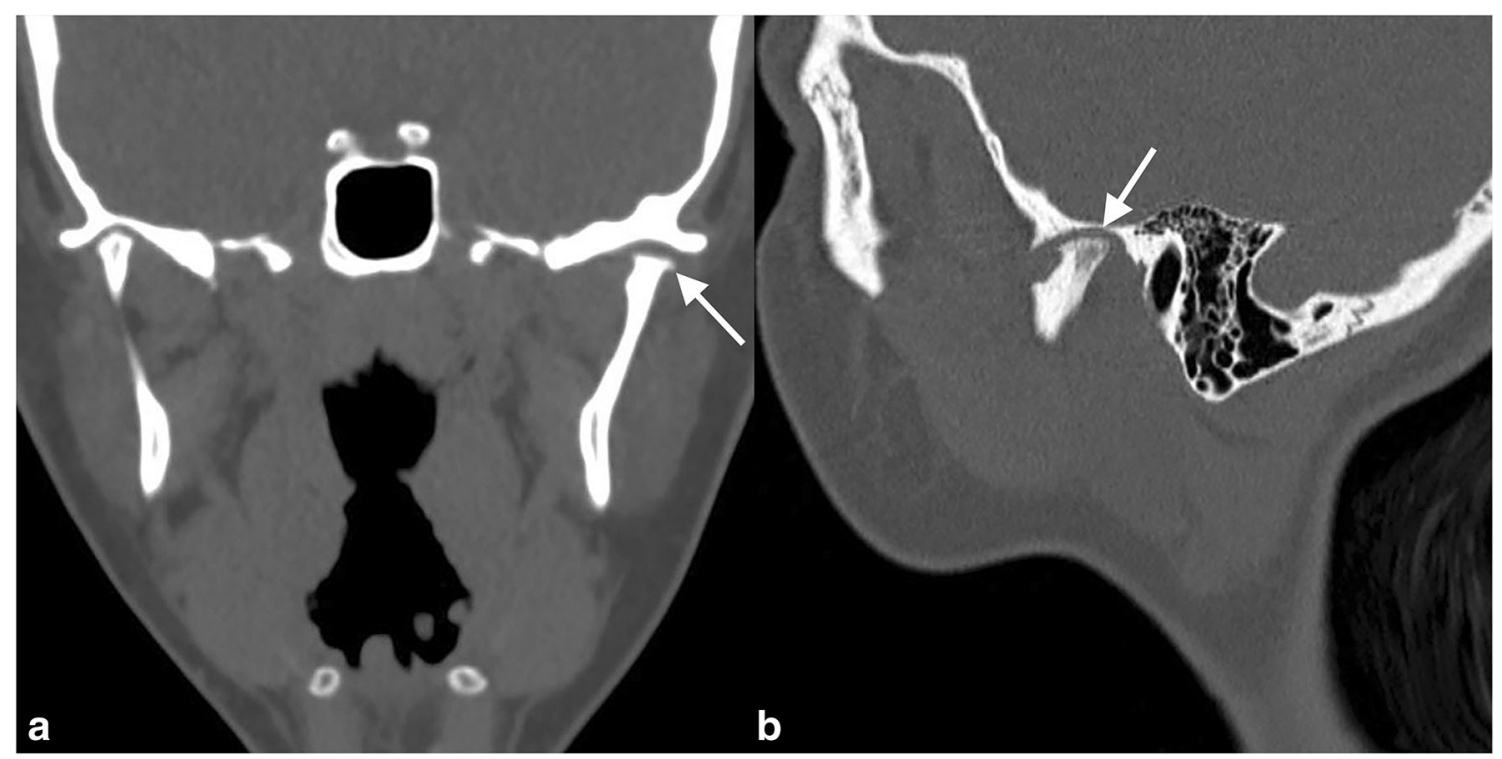

Fig. 1 An 18-year-old girl with long-standing TMJ arthritis showing chronic condylar bony abnormalities of the left temporomandibular joint including flattening of the temporal fossa and the mandibular condyle (arrows) on (a) coronal and (b) sagittal CT images

\section{Spine}

In children with JIA and spine involvement, the cervical spine is most frequently involved. Up to $65 \%$ of JIA patients have symptoms of the cervical spine [18-20]. There is also an association between TMJ and cervical spine arthritis [21]. The atlanto-occipital and atlanto-axial joints are synovial joints and are prone to rheumatoid inflammation [22]. Cervical spine arthritis can sometimes follow a severe course, resulting in morphological change and functional impairment when left untreated [23]. The clinical signs and symptoms in children with spinal involvement differ from those in adults [24]. Since inflammatory back pain being less prominent in children, sacroiliac (SI) joint arthritis/enthesitis, involved infrequently, and hip and peripheral joint arthritis/enthesitis are commonly seen in children with enthesitis-related arthritis (ERA), and inflammatory abnormalities involving the spine can be missed in children [25]. As with TMJ arthritis, relatively minor subjective complaints are often associated with extensive imaging abnormalities [26]; therefore, evaluating the whole spine can be helpful to increase diagnostic accuracy. Thoracic and lumbar spinal inflammatory lesions, which are relatively common in adults, are rare in children [24, 25], especially in the early phase of the disease and in the absence of sacroiliitis [24].

Radiography is useful for assessing malalignment, functional impairment, growth disturbances or morphological bony changes [27, 28]. Apophyseal joint ankylosis, anterior atlanto-axial subluxation and atlantoaxial impaction are serious complications of rheumatoid arthritis, but these are rare in children [29]. Atlanto-axial diastases may be normal in paediatric patients; therefore, dynamic radiographic views must be interpreted with caution. Radiography is not sensitive for detecting early joint changes [55].

Table 1 Joint-specific paediatric normal references by modality

\begin{tabular}{llll}
\hline Joint & Radiography & Ultrasound & MRI \\
\hline TMJ & NA & NA & Kottke et al [15] \\
Spine & NA & NA & NA \\
SI joint & NA & NA & Chauvin et al [30] \\
Wrist & Greulich and Pyle [31] & Rosendahl et al [32] & Ording Muller et al [35] \\
& & Collado et al [33] & Avenarius et al [36] \\
Hip & NA & Roth et al [34] & NA \\
Knee & NA & Rohrschneider et al [37] & Hemke et al [41] \\
& & Robben [38] & Collado et al [33] \\
& & Roth et al [34] & Keshava et al [39] \\
\end{tabular}


Table 2 Joint-specific scoring systems for evaluating inflammatory and/or destructive changes by modality

\begin{tabular}{|c|c|c|c|}
\hline Joint & Radiography & Ultrasound & MRI \\
\hline TMJ & NA & NA & $\begin{array}{l}\text { Koos et al [42] } \\
\text { Vaid et al [21] }\end{array}$ \\
\hline Spine & NA & NA & NA \\
\hline SI joint & NA & NA & $\begin{array}{l}\text { Weiss et al [43] } \\
\text { Herregods et al [44] }\end{array}$ \\
\hline Wrist & $\begin{array}{l}\text { Adapted Sharp/van der Heijde [46] } \\
\text { Poznanski score [47] }\end{array}$ & NA & $\begin{array}{l}\text { Malattia et al [45] } \\
\text { Damasio et al [49] }\end{array}$ \\
\hline Hip & $\begin{array}{l}\text { Shelmerdine et al [50] } \\
\text { Bertamino et al [51] }\end{array}$ & NA & NA \\
\hline Knee & NA & CARRA JIA Ultrasound Workgroup [52] & Juvenile Arthritis MRI Score (JAMRIS) [53, 54] \\
\hline
\end{tabular}

Concerning the cervical joints, there are no published studies on the use of US in JIA.

Contrast-enhanced MRI is the modality of choice for detecting early, often subclinical cervical spine arthritis, with joint effusion, enhancing thickened synovium, and bone marrow oedema. MRI can also evaluate late stage changes such as erosions, dens deformation, subluxations, joint ankylosis and neural compression $[23,26,56,57]$. In adults, bone marrow oedema is considered a predictor for erosions [58]. In adults, the Assessment in Spondyloarthritis International Society (ASAS) identified features that could indicate a positive spinal MRI for spondyloarthritis (SpA) [59]. However, these definitions developed for adults have not yet been validated in children, with no endorsed scoring system available for MRI evaluation of arthritis of the spine in children [60]. An example of an MRI protocol is given in Supplementary File 1.

Point to consider Radiography of the spine is still suggested in JIA patients with clinical involvement of the spine, but in terms of diagnostic accuracy in early disease and radiation protection, MRI of the whole spine can be considered at baseline.

Rationale Ultrasound of the SI and spinal joints is neither practical nor reliable. Radiographs may depict late structural damage and syndesmophytes, whilst identifying anatomic variants and abnormalities which may give alternative mechanical explanations for pathology. MRI depicts bony and soft tissue features of both early and chronic diseases and can both quantify disease burden and monitor treatment effect.

Controversies/future developments (a) Can low-dose CT replace or supplement radiography in order to depict structural bony changes at an earlier stage? (b) Should screening MR images of the cervical spine be included in a TMJ arthritis protocol?

\section{Sacroiliac joints}

The SI joints are affected in approximately $30 \%$ of children with the ERA subtype of JIA. Sacroiliitis is usually not seen in

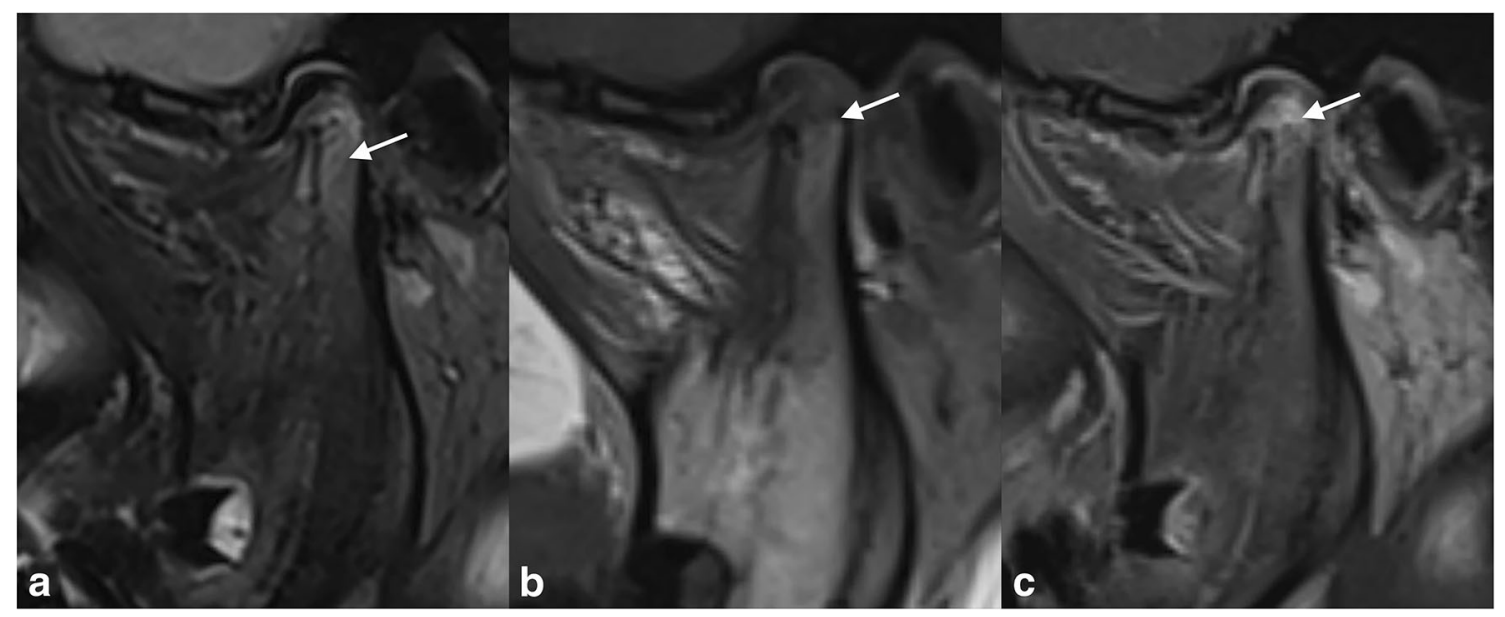

Fig. 2 A 13-year-old girl with JIA and active TMJ arthritis. MRI of the TMJ with (a) a sagittal oblique T2-weighted fat-saturated image showing bone marrow oedema (hyper-intense signal on T2-weighted images (arrow)) in the TMJ condyle, (b) a sagittal oblique T1-weigted image showing bone marrow oedema (hypo-intense signal on T1-weighted images) and condylar flattening (arrow) and (c) a sagittal oblique T1weighted fat-saturated post-Gd image showing joint and condylar enhancement (arrow) 
the early course of the disease; children typically first present with enthesitis and lower extremity peripheral arthritis prior to developing SI joint involvement. Despite this, early identification of sacroiliitis is crucial, as treatment options are not only different than those for peripheral juvenile $\mathrm{SpA}$, but there is also markedly increased long-term disability too. Clinical assessment of the SI joints is difficult, with non-specific and subjective symptoms that may occur rather late in the disease course.

Radiographs have limited value in screening for sacroiliitis in children and result in a significant proportion of both false negative and positive findings compared to MRI [ 61-64]. As discussed earlier, the usefulness of US in axial joints is limited.

MRI is the imaging modality of choice for detecting early inflammatory change of the SI joints. Active features of sacroiliitis can include bone marrow oedema, enthesitis and capsulitis/synovitis (Fig. 3). Features of structural damage include erosions, fatty deposition, sclerosis and ankylosis. According to the ASAS definition of sacroiliitis suggestive of $\mathrm{SpA}$ in adults, bone marrow oedema must be periarticular in location [65]. Although water-sensitive sequences alone are highly sensitive for the detection of active sacroiliitis, contrast-enhanced (fat-saturated) T1-weighted sequences may be helpful to differentiate joint fluid from synovitis $[4,66$, 67]. See Supplementary File 1 for an example of an MRI protocol. In contrast to sacroiliitis in adults, bone marrow oedema is highly specific for juvenile $\mathrm{SpA}$ and is less dependent on other features of SpA for imaging diagnosis. The hips are commonly affected in ERA; therefore, they should be included in MRI of SI joints [64]. In adults, there are scoring systems, of which the Spondyloarthritis Research Consortium of Canada (SPARCC) scoring system is most widely accepted. The early studies in children are promising and describe good feasibility and reliability of the SPARCC scoring systems; however, these are not yet widely used and some adaptations may be necessary [43-45] (Table 2). Developing reliable paediatric-specific definition for sacroiliitis is a difficult task currently undergoing active study [44, 68]. A paediatric-specific scoring system is being developed by the Outcome Measures in Rheumatology Clinical Trials (OMERACT) MRI in JIA working group [60].

Point to consider Children with suspected axial SpA could have MRI performed to include SI joints and hips. Including screening MR images of the whole spine is preferred.

Rationale Radiography has poor sensitivity and specificity for detecting sacroiliitis. Performing MRI of only a limited area of the SI joints may miss clinically silent disease of the hips and spine which adds to the understanding of overall disease burden and may affect prognosis.

Controversies/future developments (a) In growing children, it can be difficult to differentiate normal variants from pathology. How should we, therefore, formally define a positive scan in each region, particularly when normal standards are lacking? (b) Are there any situations in which gadolinium is crucial for MRI of the SI joints in children?

\section{Peripheral joints}

\section{Wrist}

Wrist involvement in JIA occurs in about $25 \%$ of patients, increasing to $40 \%$ after 5 years of disease [69]. In JIA, early involvement of the wrist, distal small joint arthritis and a symmetric arthritis are poor prognostic factors [55]. Since early recognition and proper treatment can improve clinical outcome [70], imaging plays an important role in JIA patients with hand and wrist involvement.

Conventional radiography has been considered the basis to identify growth abnormalities and late destructive change [71]. Also, cartilage loss is hard to evaluate in growing children.

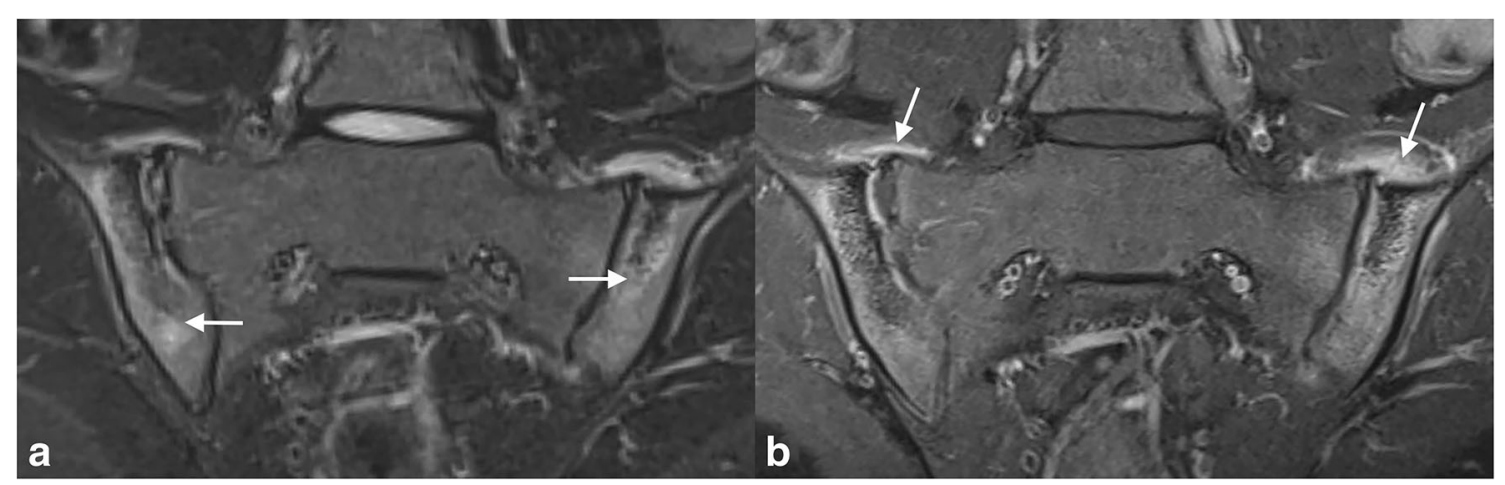

Fig. 3 A 16-year-old boy with JIA, active sacroiliitis and an MRI showing (a) a coronal oblique STIR image showing bone marrow oedema (arrow) in, predominantly, the iliac side of the sacroiliac joints and capsulitis and (b) a coronal oblique T1-weigted fat-saturated post-Gd

image showing bone marrow enhancement, joint enhancement and capsulitis (arrow). In this case, capsulitis can be seen as hyper-intense T2-weighted signal with enhancement at the T1-weighted fat-saturated post-Gd image at the cranial site of the sacroiliac joints 
Several scoring systems for evaluating structural damage in children with JIA and hand/wrist involvement exist, of which an adapted version of the Sharp/van der Heijde score has been shown to be both reliable and valid for progressive change [46] (Table 2). The Poznanski index is a useful measure of late change [47]; particularly in younger children, bone damage can appear as squaring or deformity of the carpal bones and epiphyses rather than as true erosive change [71]. Conventional radiography is superior to MRI in this regard [55, 72].

US is helpful for the assessment of inflammation as well as for guidance in joint injections. It has been shown to reliably detect synovitis, tenosynovitis, cartilage damage and bone erosions in the wrist and metacarpal joints of JIA patients [73]. Currently, no agreed scoring systems exist; however, this is work-in-progress [71] (Table 2). Typically, there is a thickened, hyperaemic synovial membrane and a joint effusion. Some standards for synovial thickness and the amount of joint fluid exist for the wrist (Table 1). Definitions of age-dependent ultrasonographic anatomy and standardised approach for ultrasound in children have been suggested [33, 34].

MRI is the most validated method for assessment of inflammation, showing synovitis, tenosynovitis and effusion [71]. It also shows bone marrow oedema and late destructive change [74]. There are several sequences which are helpful for the assessment of disease activity and structural change [75]. This includes pre- and post-contrast fat-saturated images (in the same plane) to differentiate an inflamed synovium from joint effusion [76] and a field of view including the distal radio-ulnar joints and the metacarpophalangeal joints $[60$, 77] (see also Supplementary File 1 for an example of an MRI protocol). The development of a MRI scoring system was initially based on the OMERACT Rheumatoid Arthritis MRI Scoring (RAMRIS) system for adults [78]. Malattia and colleagues [48] developed the first paediatric-targeted MRI scoring system. During the following years, an international effort called Health-e-Child published a revised version [49] and suggested an extension of the field of view [77] (Table 2). It is important to be aware of the high prevalence of normal variants (bony depressions (Fig. 4), bone marrow lesion-like changes and joint fluid) as this may mimic pathology in the scope of JIA $[35,36]$ (Table 1).

Point to consider Routine radiographs of the wrists/hands are recommended at diagnosis and follow-up of JIA patients with wrist/hand involvement and could be performed alongside MRI or ultrasound.

Rationale It can be hard to differentiate normal bony depressions from erosions in wrists of JIA patients. Growth disturbances of the wrist and periarticular osteoporosis in longer standing JIA are probably a more consistent hallmark of destructive change, which can be more reliably evaluated on conventional radiographs.

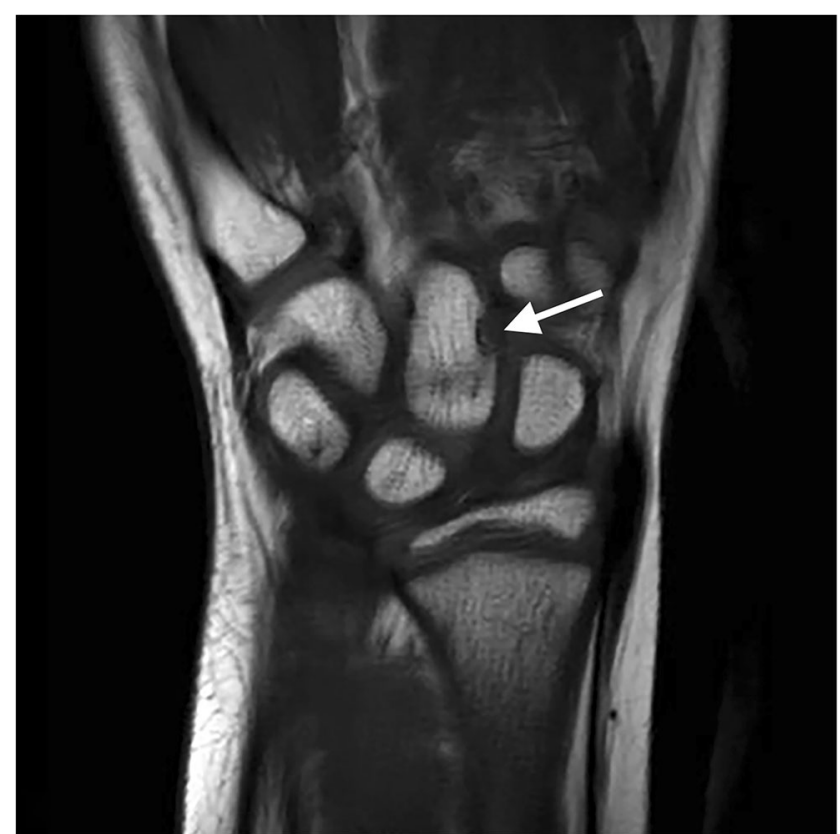

Fig. 4 A 10-year-old healthy girl with a coronal T1-weighted image showing a bony depression on the radial side of the capitate (arrow). This is a normal depression that can be seen in the carpal bones of growing children and should not be mistaken for pathology (erosive disease)

Controversies/future developments (1) Will a dedicated additional cartilage sequence help to differentiate normal variants from pathologic erosive change in the JIA wrist with more certainty? (2) Can dynamic contrast-enhanced MRI help to differentiate active from inactive inflammation from physiological increased perfusion in the joint tissue due to growth?

\section{Hip}

The hip is affected in around $20-50 \%$ of the children with JIA $[79,80]$ and can cause irreversible destructive change within 5 years of diagnosis [81].

Imaging findings are those of inflammation (synovitis, tendinitis and bursitis) and effusions before peri-articular bony changes (bone marrow oedema) [82]. Further disease progression may lead to growth disturbances as well as destruction of cartilage and bone. Growth disturbances are best imaged radiographically. The only child-specific scoring systems available are those of Bertamino et al [51] and Shelmerdine et al [50] (Table 2).

Normal US reference values for synovial thickness and the presence of visible joint fluid were published decades ago [37, 38] (Table 1). The European Society of Musculoskeletal Radiology (ESSR) provides a free online guide with anatomical correlation and ultrasound features of the hip joint [83]. However, age-related variations in thickness of cartilage, appearance of ossification centres and normal epiphyseal and metaphyseal vessels can mimic pathology [82]. In cases of inflammation, there is a thickened, often villous and 
hyperaemic synovium and an effusion. Validated US scoring systems for the JIA hip are lacking (Table 2).

MRI is the only modality that can assess both the soft tissue and bone marrow changes seen in JIA [82] (Fig. 5). MRI sequences will usually include one T1-weighted sequence (non-fat-saturated, to assess for appropriate bone marrow fatty conversion), a water-sensitive sequence (to assess for bone marrow oedema and joint effusion) and pre- and post-contrast fat-saturated T1-weighted sequences (to assess for synovial enhancement and thickening). Timing of post-contrast images should be standardised [76, 84]. An example of an MRI protocol is given in Supplementary File 1. Currently, a validated MRI scoring system for the hips has not been established (Table 2). Porter-Young et al [85] have shown the most reliable MRI parameters on which a scoring system might be based.

Point to consider Routine radiographs of the hips could be performed at presentation and follow-up of JIA patients with hip involvement. MRI could be considered at baseline and, potentially, also at follow-up when ultrasound is equivocal.

Rationale Radiographs are important for the assessment of growth abnormalities, and ultrasound is easy to use for the assessment of active inflammation in children. When findings are equivocal, an MRI, preferably with gadolinium, could be performed to confirm the diagnosis and for narrowing the differential diagnoses.

Controversies/future developments Will a dedicated additional cartilage sequence be helpful in the detection of early destructive change?

\section{Knee}

The knee joint is clinically the most commonly affected joint in JIA [69].
Radiography remains important, particularly in narrowing the differential diagnosis and in establishing a baseline for follow-up. It can provide information on growth disturbances $[55,86]$. Because of the availability of more effective treatment options and the relatively large amount of epiphyseal cartilage in knees of growing children, bone erosions in knee joints in JIA patients are relatively rare.

US plays an important role in differential diagnosis and can be useful for treatment monitoring as well as for guiding joint injections [52, 87]. Knee US has some limitation. The central recess, whilst being the location most commonly affected by synovitis in the knee, is difficult to evaluate sonographically [88]. Recently, a paediatric-specific US scoring system for the knee has been proposed by the Childhood Arthritis and Rheumatology Research Alliance (CARRA) JIA Ultrasound Workgroup [52].

MRI is the preferred imaging modality for the assessment of inflammatory and destructive changes in JIA patients with knee involvement. The main imaging features include synovial thickening, joint effusion and bone marrow oedema. Although relatively rare, cartilage loss and bone erosion may be observed. Synovitis is the principal pathological process in JIA, and its presence in the knee is associated with the clinical onset of JIA [89]. Therefore, pre- and post-contrast sequences with standardised timing of post-contrast images are warranted to accurately evaluate synovitis in the knee joint $[76,84$, 90]. An example of an MRI protocol for the knee in JIA is given in Supplementary File 1. In recent years, a paediatricspecific MRI scoring system for the knee has been developed and validated (the Juvenile Arthritis MRI Scoring (JAMRIS)) [53, 54] (Table 2). MRI of healthy children may show an enhancing synovial membrane $(<2 \mathrm{~mm})$, some joint fluid and, in some cases, high-signal intensity bone marrow changes in the patellar apex [41] (Table 1). Future research is expected to evaluate the suitability of advanced quantitative MRI techniques for evaluating inflammatory and destructive change in the JIA knee, including dynamic contrast-enhanced

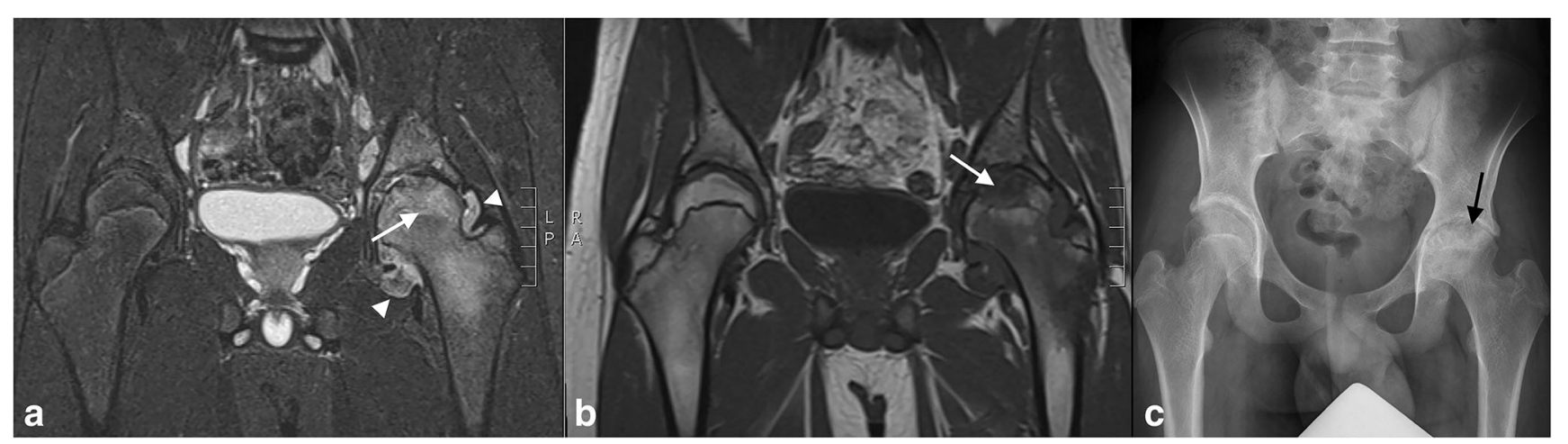

Fig. 5 A 15-year-old boy with juvenile idiopathic arthritis and hip involvement with (a) a coronal T2-weighted fat-saturated image showing synovial thickening (arrow heads) in the left hip with extensive bone marrow oedema in the femoral head (arrow), (b) a coronal T1-weigted image showing irregular cortical linings in the scope of erosive changes (arrow) and (c) the corresponding X-ray showing joint space narrowing and cortical irregularities/erosive change in the femoral head (arrow) 


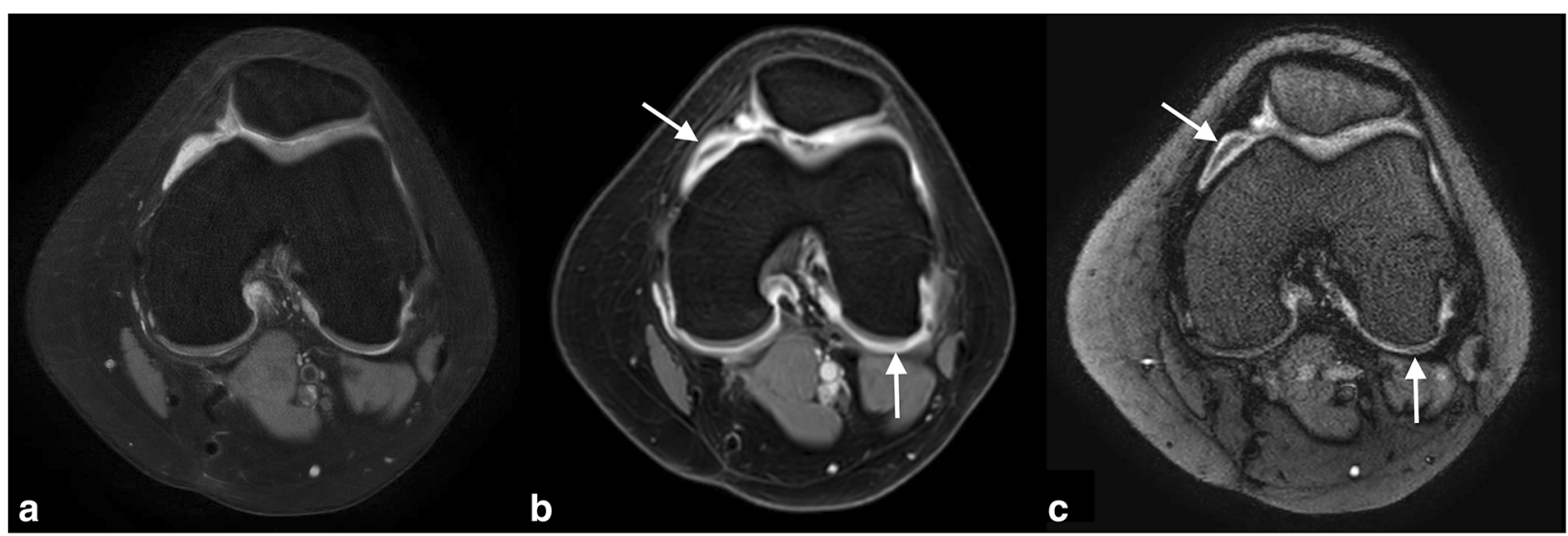

Fig. 6 A 14-year-old boy with oligo-articular JIA and knee arthritis. MRI of the knee with (a) an axial T2-weighted fat-saturated image, (b) an axial T1-weigted fat-saturated post-Gd image showing an enhancing thickened

(DCE)-MRI, T2 mapping, T1 rho and diffusion-weighted imaging (DWI) [91-97]. Now, these advanced imaging techniques are used mainly in the setting of research and, to a lesser extent, in daily practice. synovial membrane retro-patellar (arrow) and posterior of the condyles (arrow) and (c) an axial double inversion recovery (DIR)-weighted Gdfree image showing a similar picture (arrows)

Point to consider In children with a suspected inflammatory arthropathy and knee involvement, pre- and post-contrast MR images can be helpful for the evaluation of the degree of synovitis. To ensure accurate comparison between previous

Table 3 Summary

\begin{tabular}{llrl}
\hline Joint & Conventional radiography & Ultrasound & MRI \\
\hline TMJ & Not indicated & Not indicated & For patients with clinical suspicion of TMJ \\
& & JIA, fluid-sensitive, closed and open mouth \\
views are suggested. Contrast-enhanced & sequences are proposed since it can be \\
& & $\begin{array}{l}\text { helpful in evaluating synovial } \\
\text { inflammation }\end{array}$ & Consider contrast-enhanced MRI at baseline
\end{tabular}

Spine disturbances and bony changes

Take care in interpretation of dynamic images

SI joint Not indicated

Wrist

High-resolution radiographs of wrists and hands at diagnosis and follow-up, especially for evaluating growth disturbances

Hip At diagnosis to exclude other causes of joint pain,

helps to evaluate growth

disturbances and destructive change

Knee At diagnosis to exclude other causes of joint pain, helps to evaluate growth disturbances
Not indicated

Consider contrast-enhanced MRI at baseline
For the detection of joint effusion, synovitis and tenosynovitis

Aiding joint injections

For detection of effusion and synovitis and aiding joint injections

For the assessment of joint effusions, synovitis and aiding joint injections
Consider MRI in children with suspected axial SpA. MRI could include SI joints and hips and consider screening MRI of the spine

MRI for assessment of effusions and synovitis Structural abnormalities can be detected, but be aware of normal variants mimicking disease

Consider MRI at baseline and at follow-up when ultrasound is equivocal

In children with a suspected inflammatory arthropathy and knee involvement, pre- and post-contrast MRI for evaluation of synovitis is suggested for the evaluation of the degree of synovitis. Structural abnormalities can be detected.

Standardise timing after contrast for all imaging to ensure comparability is recommended

\footnotetext{
${ }^{a}$ The potential risks associated with exposure to ionising radiation must always be considered when using conventional radiography
} 
and present examinations, timing of post-contrast MR images should be standardised.

Rationale Diagnostic accuracy of unenhanced MRI for evaluating knee synovitis is limited compared to contrast-enhanced MRI. However, the timing of post-contrast images strongly influences the enhancement, synovial thickness and total inflammation scores in the assessment of synovitis.

Controversies/future developments Should we aim for a broader clinical applicability of non-contrast-enhanced MRI techniques for the evaluation of knee synovitis, such as DWI and double inversion recovery imaging (Fig. 6)?

\section{Conclusion}

In this article, we discussed paediatric-specific imaging characteristics of the most commonly involved and clinically important joints in JIA. Conventional radiographs have a lower sensitivity and specificity for disease activity, early arthritic disease detection and monitoring response to therapies, in addition to exposure to ionising radiation (Table 3 ). Nonetheless, radiography is valuable in the assessment of growth plates and epiphyses in the hand, to detect peri-articular osteoporosis in longer-standing JIA as well as spinal alignment.

Radiation protection is a priority in children with JIA; thus, in dedicated centres, the use of ultrasound or MRI in peripheral joints affected by JIA should be considered. Particularly in peripheral joints, ultrasound can be helpful for the assessment of inflammation, in differential diagnosis, and it can be useful for guiding joint injections. In JIA, MRI is the most validated technique for the assessment of inflammation and early destructive change. MRI could be of added value depending on local resources and expertise, but it should be considered as the modality of choice to assess the axial skeleton or where the clinical presentation overlaps with JIA, such as in osteomyelitis. Further imaging with radiographs and/or MRI should be guided by the preliminary findings, inconclusive US, atypical clinical presentation, chronic disease or when assessing response to therapy.

Finally, we have provided clinically applicable joint-specific points to consider on behalf of the ESSR arthritis subcommittee and the ESPR musculoskeletal imaging taskforce, highlighting areas of existing controversy/need for further study.

Funding Information The authors state that this work has not received any funding.

\section{Compliance with ethical standards}

Guarantor The scientific guarantor of this publication is Dr. Robert Hemke.
Conflict of interest The authors declare that they have no conflict of interest.

Statistics and biometry No complex statistical methods were necessary for this paper.

Informed consent Written informed consent was not required for this study because the manuscript can be considered a review article.

Ethical approval Institutional review board approval was not required because the manuscript can be considered a review article.

Methodology $•$ Multicentre study

Open Access This article is licensed under a Creative Commons Attribution 4.0 International License, which permits use, sharing, adaptation, distribution and reproduction in any medium or format, as long as you give appropriate credit to the original author(s) and the source, provide a link to the Creative Commons licence, and indicate if changes were made. The images or other third party material in this article are included in the article's Creative Commons licence, unless indicated otherwise in a credit line to the material. If material is not included in the article's Creative Commons licence and your intended use is not permitted by statutory regulation or exceeds the permitted use, you will need to obtain permission directly from the copyright holder. To view a copy of this licence, visit http://creativecommons.org/licenses/by/4.0/.

\section{References}

1. Billiau AD, Hu Y, Verdonck A, Carels C, Wouters C (2007) Temporomandibular joint arthritis in juvenile idiopathic arthritis: prevalence, clinical and radiological signs, and relation to dentofacial morphology. J Rheumatol 34:1925-1933. https://doi. org/10.1148/rg.2017160078

2. Navallas M, Inarejos EJ, Iglesias E, Lee GYC,Rodríguez N, Antón $\mathrm{J}$ (2017) MR imaging of the temporomandibular joint in juvenile idiopathic arthritis: technique and findings. Radiographics 37:595612. https://doi.org/10.1148/rg.2017160078

3. Küseler A, Pedersen TK, Herlin T, Gelineck J (1998) Contrast enhanced magnetic resonance imaging as a method to diagnose early inflammatory changes in the temporomandibular joint in children with juvenile chronic arthritis. J Rheumatol 25:1406-1412. https://doi.org/10.1148/rg.2017160078

4. Sheybani EF, Khanna G, White AJ, Demertzis JL (2013) Imaging of juvenile idiopathic arthritis:a multimodality approach. Radiographics 33:1253-1273. https://doi.org/10.1148/rg. 335125178

5. Weiss PF, Arabshahi B, Johnson A et al (2008) High prevalence of temporomandibular joint arthritis at disease onset in children with juvenile idiopathic arthritis, as detected by magnetic resonance imaging but not by ultrasound. Arthritis Rheum 58:1189-1196. https://doi.org/10.1002/art.23401

6. Cannizzaro E, Schroeder S, Müller LM, Kellenberger CJ, Saurenmann RK (2011) Temporomandibular joint involvement in children with juvenile idiopathic arthritis. J Rheumatol 38:510 515. https://doi.org/10.3899/jrheum. 100325

7. Keller H, Müller LM, Markic G et al (2015) Is early TMJ involvement in children with juvenile idiopathic arthritis clinically detectable? Clinical examination of the TMJ in comparison with contrast enhanced MRI in patients with juvenile idiopathic arthritis. Pediatr Rheumatol Online J 13:56. https://doi.org/10.1186/s12969-0150056-2 
8. Larheim TA, Abrahamsson A-K, Kristensen M, Arvidsson LZ (2015) Temporomandibular joint diagnostics using CBCT. Dentomaxillofac Radiol 44:20140235. https://doi.org/10.1259/ dmfr.20140235

9. Miller E, Inarejos Clemente EJ, Tzaribachev N et al (2018) Imaging of temporomandibular joint abnormalities in juvenile idiopathic arthritis with a focus on developing a magnetic resonance imaging protocol. Pediatr Radiol 48:792-800. https://doi.org/10.1007/ s00247-017-4005-8

10. Ferraz AML, Devito KL, Guimarães JP (20 12 ) Temporomandibular disorder in patients with juvenile idiopathic arthritis: clinical evaluation and correlation with the findings of cone beam computed tomography. Oral Surg Oral Med Oral Pathol Oral Radiol 114:e51-e57. https://doi.org/10.1016/j.oooo. 2012.02.010

11. Kirkhus E, Gunderson RB, Smith H-J et al (2016) Temporomandibular joint involvement in childhood arthritis: comparison of ultrasonography-assessed capsular width and MRIassessed synovitis. Dentomaxillofac Radiol 45:20160195. https:// doi.org/10.1259/dmfr.20160195

12. Müller L, Kellenberger CJ, Cannizzaro E et al (2009) Early diagnosis of temporomandibular joint involvement in juvenile idiopathic arthritis: a pilot study comparing clinical examination and ultrasound to magnetic resonance imaging. Rheumatology (Oxford) 48: 680-685. https://doi.org/10.1093/rheumatology/kep068

13. Zwir LF, Terreri MT, do Amaral E, Castro A et al (2019) Is power Doppler ultrasound useful to evaluate temporomandibular joint inflammatory activity in juvenile idiopathic arthritis? Clin Rheumatol. https://doi.org/10.1007/s10067-019-04731-x

14. Kellenberger CJ, Junhasavasdikul T, Tolend M, Doria AS (2018) Temporomandibular joint atlas for detection and grading of juvenile idiopathic arthritis involvement by magnetic resonance imaging. Pediatr Radiol 48:411-426. https://doi.org/10.1007/s00247-0174000-0

15. Kottke R, Saurenmann RK, Schneider MM, Müller L, Grotzer MA, Kellenberger CJ (2015) Contrast-enhanced MRI of the temporomandibular joint: findings in children without juvenile idiopathic arthritis. Acta Radiol 56:1145-1152. https://doi.org/10.1177/ 0284185114548506

16. Smith HJ, Larheim TA, Aspestrand F (1992) Rheumatic and nonrheumatic disease in the temporomandibular joint: gadolinium-enhanced MR imaging. Radiology 185:229-234. https://doi. org/10.1148/radiology.185.1.1523314

17. Kirkhus E, Arvidsson LZ, Smith H-J, Flatø B, Hetlevik SO, Larheim TA (2016) Disk abnormality coexists with any degree of synovial and osseous abnormality in the temporomandibular joints of children with juvenile idiopathic arthritis. Pediatr Radiol 46:331341. https://doi.org/10.1007/s00247-015-3493-7

18. Wolfs JFC, Arts MP, Peul WC (2014) Juvenile chronic arthritis and the craniovertebral junction in the paediatric patient: review of the literature and management considerations. Adv Tech Stand Neurosurg 41:143-156. https://doi.org/10.1007/978-3-319-0183007

19. Espada G, Babini JC, Maldonado-Cocco JA, García-Morteo O (1988) Radiologic review: the cervical spine in juvenile rheumatoid arthritis. Semin Arthritis Rheum 17:185-195

20. Laiho K, Savolainen A, Kautiainen H, Kekki P, Kauppi M (2002) The cervical spine in juvenile chronic arthritis. Spine J 2:89-94. https://doi.org/10.1016/S1529-9430(02)00151-1

21. Vaid YN, Daniel Dunnavant F, Royal SA, Beukelman T, Stoll ML, Cron RQ (2014) Imaging of the temporomandibular joint in juvenile idiopathic arthritis. Arthritis Care Res 66:47-54. https://doi. org/10.1002/acr.22177

22. Reiter MF, Boden SD (1998) Inflammatory disorders of the cervical spine. Spine (Phila Pa 1976) 23:2755-2766
23. Ključevšek D, Emeršič N, Toplak N, Avčin T (2017) Clinical and MRI outcome of cervical spine lesions in children with juvenile idiopathic arthritis treated with anti-TNF $\alpha$ drugs early in disease course. Pediatr Rheumatol Online J 15:38. https://doi.org/10.1186/ s12969-017-0173-1

24. Hofer M (2006) Spondylarthropathies in children-are they different from those in adults? Best Pract Res Clin Rheumatol 20:315-328. https://doi.org/10.1016/j.berh.2005.12.001

25. Sudoł-Szopińska I, Eshed I, Jans L, Herregods N, Teh J, Vojinovic J (2018) Classifications and imaging of juvenile spondyloarthritis. J Ultrason 18:224-233. https://doi.org/10.15557/JoU.2018.0033

26. Hospach T, Maier J, Müller-Abt P, Patel A, Horneff G, von Kalle T (2014) Cervical spine involvement in patients with juvenile idiopathic arthritis - MRI follow-up study. Pediatr Rheumatol Online J 12:9. https://doi.org/10.1186/1546-0096-12-9

27. Joaquim AF, Ghizoni E, Tedeschi H, Appenzeller S, Riew KD (2015) Radiological evaluation of cervical spine involvement in rheumatoid arthritis. Neurosurg Focus 38:E4. https://doi.org/10. 3171/2015.1.FOCUS14664

28. Elhai M, Wipff J, Bazeli R et al (2013) Radiological cervical spine involvement in young adults with polyarticular juvenile idiopathic arthritis. Rheumatology (Oxford) 52:267-275. https://doi.org/10. 1093/rheumatology/kes054

29. Kjellberg H, Pavlou I (2011) Changes in the cervical spine of children with juvenile idiopathic arthritis evaluated with lateral cephalometric radiographs: a case control study. Angle Orthod 81:447452. https://doi.org/10.2319/060310-302.1

30. Chauvin NA, Xiao R, Brandon TG et al (2019) MRI of the sacroiliac joint in healthy children. AJR Am J Roentgenol:1-7. https:// doi.org/10.2214/AJR.18.20708

31. Greulich W, Pyle I (1959) Radiographic atlas of skeletal development of the hand and wrist. Stanford University Press, London

32. Rosendahl K, Bruserud IS, Oehme N et al (2018) Normative ultrasound references for the paediatric wrist; dorsal soft tissues. RMD open 4:e000642. https://doi.org/10.1136/rmdopen-2017-000642

33. Collado P, Vojinovic J, Nieto JC et al (2016) Toward standardized musculoskeletal ultrasound in pediatric rheumatology: normal agerelated ultrasound findings. Arthritis Care Res (Hoboken) 68:348356. https://doi.org/10.1002/acr.22670

34. Roth J, Jousse-Joulin S, Magni-Manzoni S et al (2015) Definitions for the sonographic features of joints in healthy children. Arthritis Care Res (Hoboken) 67:136-142. https://doi.org/10.1002/acr. 22410

35. Müller L-SO, Avenarius D, Damasio B et al (2011) The paediatric wrist revisited: redefining MR findings in healthy children. Ann Rheum Dis 70:605-610. https://doi.org/10.1136/ard.2010.135244

36. Avenarius DMF, Ording Müller L-S, Eldevik P, Owens CM, Rosendahl K (2012) The paediatric wrist revisited-findings of bony depressions in healthy children on radiographs compared to MRI. Pediatr Radiol 42:791-798. https://doi.org/10.1007/s00247-0122354-x

37. Rohrschneider WK, Fuchs G, Tröger J (1996) Ultrasonographic evaluation of the anterior recess in the normal hip: a prospective study on 166 asymptomatic children. Pediatr Radiol 26:629-634

38. Robben S (1993) Ultrasound and hip joint effusion. Eur J Radiol 17:134

39. Keshava SN, Gibikote SV, Mohanta A et al (2015) Ultrasound and magnetic resonance imaging of healthy paediatric ankles and knees: a baseline for comparison with haemophilic joints. Haemophilia 21(3):e210-e222. https://doi.org/10.1111/hae.12614

40. Spannow AH, Pfeiffer-Jensen M, Andersen NT, Herlin T, Stenbøg E (2010) Ultrasonographic measurements of joint cartilage thickness in healthy children: age- and sex-related standard reference values. J Rheumatol 37:2595-2601. https://doi.org/10.3899/ jrheum.100101 
41. Hemke R, van den Berg JM, Nusman CM et al (2018) Contrastenhanced MRI findings of the knee in healthy children; establishing normal values. Eur Radiol 28:1167-1174. https://doi.org/10.1007/ s00330-017-5067-6

42. Koos B, Tzaribachev N, Bott S, Ciesielski R, Godt A (2013) Classification of temporomandibular joint erosion, arthritis, and inflammation in patients with juvenile idiopathic arthritis. J Orofac Orthop 74:506-519. https://doi.org/10.1007/s00056-0130166-8

43. Weiss PF, Maksymowych WP, Lambert RG et al (2018) Feasibility and reliability of the Spondyloarthritis Research Consortium of Canada sacroiliac joint inflammation score in children. Arthritis Res Ther 20:56. https://doi.org/10.1186/s13075-018-1543-x

44. Herregods N, Dehoorne J, Van den Bosch F et al (2017) ASAS definition for sacroiliitis on MRI in SpA: applicable to children? Pediatr Rheumatol Online J 15:24. https://doi.org/10.1186/s12969017-0159-Z

45. Panwar J, Tse SMLL, Lim L et al (2019) Spondyloarthritis research consortium of Canada scoring system for sacroiliitis in juvenile spondyloarthritis/enthesitis-related arthritis: A reliability, validity, and responsiveness study. J Rheumatol 46:636-644. https://doi. org/10.3899/jrheum.180222

46. Ravelli A, Ioseliani M, Norambuena X et al (2007) Adapted versions of the Sharp/van der Heijde score are reliable and valid for assessment of radiographic progression in juvenile idiopathic arthritis. Arthritis Rheum 56:3087-3095. https://doi.org/10.1002/art. 22835

47. Poznanski AK, Hernandez RJ, Guire KE, Guire KE, Bereza UL, Garn SM (1978) Carpal length in children-a useful measurement in the diagnosis of rheumatoid arthritis and some concenital malformation syndromes. Radiology 129:661-668

48. Malattia C, Damasio MB, Pistorio A et al (2011) Development and preliminary validation of a paediatric-targeted MRI scoring system for the assessment of disease activity and damage in juvenile idiopathic arthritis. Ann Rheum Dis 70:440-446. https://doi.org/10. 1136/ard.2009.126862

49. Damasio MB, Malattia C, Tanturri de Horatio L et al (2012) MRI of the wrist in juvenile idiopathic arthritis: proposal of a paediatric synovitis score by a consensus of an international working group. Results of a multicentre reliability study. Pediatr Radiol 42:10471055. https://doi.org/10.1007/s00247-012-2392-4

50. Shelmerdine SC, Di Paolo PL, Rieter JFMM et al (2018) A novel radiographic scoring system for growth abnormalities and structural change in children with juvenile idiopathic arthritis of the hip. Pediatr Radiol 48:1086-1095. https://doi.org/10.1007/s00247018-4136-6

51. Bertamino M, Rossi F, Pistorio A et al (2010) Development and initial validation of a radiographic scoring system for the hip in juvenile idiopathic arthritis. J Rheumatol 37:432-439. https://doi. org/10.3899/jrheum.090691

52. Ting TV, Vega-Fernandez P, Oberle EJ et al (2018) A novel ultrasound image acquisition protocol and scoring system for the pediatric knee. Arthritis Care Res (Hoboken). https://doi.org/10.1002/ acr.23746

53. Hemke R, Van Rossum MAJ, Van Veenendaal M et al (2013) Reliability and responsiveness of the Juvenile Arthritis MRI Scoring (JAMRIS) system for the knee. Eur Radiol 23:10751083. https://doi.org/10.1007/s00330-012-2684-y

54. Hemke R, Tzaribachev N, Nusman CM, Van Rossum MAJ, Maas M, Doria AS (2017) Magnetic Resonance Imaging (MRI) of the knee as an outcome measure in juvenile idiopathic arthritis: An OMERACT reliability study on MRI scales. J Rheumatol 44: 1224-1230. https://doi.org/10.3899/jrheum.160821

55. Marteau P, Adamsbaum C, Rossi-Semerano L et al (2018) Conventional radiography in juvenile idiopathic arthritis: Joint recommendations from the French societies for rheumatology, radiology and paediatric rheumatology. Eur Radiol 28:39633976. https://doi.org/10.1007/s00330-018-5304-7

56. Ören B, Ören H, Osma E, Cevik N (1996) Juvenile rheumatoid arthritis: Cervical spine involvement and MRI in early diagnosis. Turk J Pediatr 38:189-194

57. Munir S, Patil K, Miller E et al (2014) Juvenile idiopathic arthritis of the axial joints: a systematic review of the diagnostic accuracy and predictive value of conventional MRI. AJR Am J Roentgenol 202:199-210. https://doi.org/10.2214/AJR.12.10475

58. Narváez JA, Narváez J, de Albert M, De Lama E, Serrallonga M, Nolla JM (2009) Bone marrow edema in the cervical spine of symptomatic rheumatoid arthritis patients. Semin Arthritis Rheum 38:281-288. https://doi.org/10.1016/j.semarthrit.2008.01.005

59. Hermann K-GA, Baraliakos X, van der Heijde DMFM et al (2012) Descriptions of spinal MRI lesions and definition of a positive MRI of the spine in axial spondyloarthritis: a consensual approach by the ASAS/OMERACT MRI study group. Ann Rheum Dis 71:12781288. https://doi.org/10.1136/ard.2011.150680

60. Nusman CM, de Horatio LT, Hemke R et al (2018) Imaging in juvenile idiopathic arthritis - international initiatives and ongoing work. Pediatr Radiol 48:828-834. https://doi.org/10.1007/s00247017-4054-z

61. Weiss PF, Xiao R, Biko DM, Chauvin NA (2016) Assessment of sacroiliitis at diagnosis of juvenile spondyloarthritis by radiography, magnetic resonance imaging, and clinical examination. Arthritis Care Res (Hoboken) 68:187-194. https://doi.org/10.1002/acr. 22665

62. Jaremko JL, Liu L, Winn NJ, Ellsworth JE, Lambert RG (2014) Diagnostic utility of magnetic resonance imaging and radiography in juvenile spondyloarthritis: evaluation of the sacroiliac joints in controls and affected subjects. J Rheumatol 41:963-970. https:// doi.org/10.3899/jrheum.131064

63. Weiss PF, Xiao R, Brandon TG et al (2018) Radiographs in screening for sacroiliitis in children: what is the value? Arthritis Res Ther 20:141. https://doi.org/10.1186/s13075-018-1642-8

64. Herregods N, Dehoorne J, Joos R et al (2015) Diagnostic value of MRI features of sacroiliitis in juvenile spondyloarthritis. Clin Radiol 70:1428-1438. https://doi.org/10.1016/j.crad.2015.09.003

65. Lambert RGW, Bakker PAC, van der Heijde D et al (2016) Defining active sacroiliitis on MRI for classification of axial spondyloarthritis: update by the ASAS MRI working group. Ann Rheum Dis 75:1958-1963. https://doi.org/10.1136/annrheumdis2015-208642

66. Althoff CE, Feist E, Burova E et al (2009) Magnetic resonance imaging of active sacroiliitis: do we really need gadolinium? Eur J Radiol 71:232-236. https://doi.org/10.1016/j.ejrad.2009.04.034

67. Herregods N, Jaremko JL, Baraliakos X et al (2015) Limited role of gadolinium to detect active sacroiliitis on MRI in juvenile spondyloarthritis. Skeletal Radiol 44:1637-1646. https://doi.org/ 10.1007/s00256-015-2211-8

68. Otobo TM, Conaghan PG, Maksymowych WP et al (2019) Preliminary definitions for sacroiliac joint pathologies in the omeract juvenile idiopathic arthritis magnetic resonance imaging score (OMERACT JAMRIS-SIJ). J Rheumatol 46:1192-1197. https://doi.org/10.3899/jrheum.181115

69. Hemke R, Nusman CM, van der Heijde DMFM et al (2014) Frequency of joint involvement in juvenile idiopathic arthritis during a 5-year follow-up of newly diagnosed patients: implications for MR imaging as outcome measure. Rheumatol. Int. 35:351-357

70. Zhao Y, Wallace C (2014) Judicious use of biologicals in juvenile idiopathic arthritis. Curr Rheumatol Rep 16:454. https://doi.org/10. 1007/s11926-014-0454-3

71. Avenarius DFM, Nusman C, Malattia C et al (2018) Current status of wrist imaging in juvenile idiopathic arthritis. Pediatr Radiol 48: 801-810. https://doi.org/10.1007/s00247-017-4063-y 
72. Ording Muller L-S, Boavida P, Avenarius D et al (2013) MRI of the wrist in juvenile idiopathic arthritis: erosions or normal variants? A prospective case-control study. Pediatr Radiol 43:785-795. https:// doi.org/10.1007/s00247-012-2575-Z

73. Ventura-Ríos L, Faugier E, Barzola L et al (2018) Reliability of ultrasonography to detect inflammatory lesions and structural damage in juvenile idiopathic arthritis. Pediatr Rheumatol Online J 16: 58. https://doi.org/10.1186/s12969-018-0275-4

74. Laurell L, Court-Payen M, Nielsen S et al (2012) Comparison of ultrasonography with Doppler and MRI for assessment of disease activity in juvenile idiopathic arthritis: a pilot study. Pediatr Rheumatol Online J 10:23. https://doi.org/10.1186/1546-0096-1023

75. Nusman CM, Ording Muller L-SS, Hemke R et al (2016) Current status of efforts on standardizing magnetic resonance imaging of juvenile idiopathic arthritis: Report from the OMERACT MRI in JIA working group and Health-e-Child. J Rheumatol 43:239-244. https://doi.org/10.3899/jrheum.141276

76. Rieter JFMM, de Horatio LT, Nusman CM et al (2016) The many shades of enhancement:timing of post-gadolinium images strongly influences the scoring of juvenile idiopathic arthritis wrist involvement on MRI. Pediatr Radiol 46:1562-1567. https://doi.org/10. 1007/s00247-016-3657-0

77. Malattia C, Tzaribachev N, van den Berg JM, Magni-Manzoni S (2018) Juvenile idiopathic arthritis - the role of imaging from a rheumatologist's perspective. Pediatr Radiol 48:785-791. https:// doi.org/10.1007/s00247-017-4014-7

78. Østergaard M, Peterfy C, Conaghan P et al (2003) OMERACT rheumatoid arthritis magnetic resonance imaging studies. Core set of MRI acquisitions, joint pathology definitions, and the OMERACT RA-MRI scoring system. J Rheumatol 30:1385-1386

79. Spencer CH, Bernstein BH (2002) Hip disease in juvenile rheumatoid arthritis. Curr Opin Rheumatol 14:536-541

80. Rostom S, Amine B, Bensabbah R, Abouqal R, Hajjaj-Hassouni N (2008) Hip involvement in juvenile idiopathic arthritis. Clin Rheumatol 27:791-794. https://doi.org/10.1007/s10067-0080853-9

81. Russo RAG, Katsicas MM (2013) Patients with very early-onset systemic juvenile idiopathic arthritis exhibit more inflammatory features and a worse outcome. J Rheumatol 40:329-334. https:// doi.org/10.3899/jrheum.120386

82. Shelmerdine SC, Di Paolo PL, Tanturri de Horatio L, Malattia C, Magni-Manzoni S, Rosendahl K (2018) Imaging of the hip in juvenile idiopathic arthritis. Pediatr Radiol 48:811-817. https://doi. org/10.1007/s00247-017-4022-7

83. Beggs I, Bianchi S, Bueno A et al (2016) ESSR musculoskeletal ultrasound technical guidelines IV. Hip. https://essr.org/contentessr/uploads/2016/10/hip.pdf. Accessed 29 Apr 2019

84. Barendregt AM, van Gulik EC, Groot PFC et al (2019) Prolonged time between intravenous contrast administration and image acquisition results in increased synovial thickness at magnetic resonance imaging in patients with juvenile idiopathic arthritis. Pediatr Radiol. https://doi.org/10.1007/s00247-018-04332-x

85. Porter-Young FM, Offiah AC, Broadley P et al (2018) Inter- and intra-observer reliability of contrast-enhanced magnetic resonance imaging parameters in children with suspected juvenile idiopathic arthritis of the hip. Pediatr Radiol 48:1891-1900. https://doi.org/10. 1007/s00247-018-4216-7

86. Miller E, Uleryk E, Doria AS (2009) Evidence-based outcomes of studies addressing diagnostic accuracy of MRI of juvenile idiopathic arthritis. AJR Am J Roentgenol 192:1209-1218. https://doi.org/ 10.2214/AJR.08.2304

87. Hemke R, Tzaribachev N, Barendregt AM et al (2018) Imaging of the knee in juvenile idiopathic arthritis. Pediatr Radiol 48:818-827. https://doi.org/10.1007/s00247-017-4015-6

88. Nusman CM, Hemke R, Schonenberg D et al (2014) Distribution pattern of MRI abnormalities within the knee and wrist of juvenile idiopathic arthritis patients: Signature of disease activity. AJR Am J Roentgenol 202:W439-W446. https://doi.org/10.2214/AJR.13. 11314

89. Hemke R, Kuijpers TW, Nusman CM et al (2015) Contrast-enhanced MRI features in the early diagnosis of juvenile idiopathic arthritis. Eur Radiol 25:3222-3229. https://doi.org/10.1007/ s00330-015-3752-x

90. Hemke R, Kuijpers TW, van den Berg JM et al (2013) The diagnostic accuracy of unenhanced MRI in the assessment of joint abnormalities in juvenile idiopathic arthritis. Eur Radiol 23:19982004. https://doi.org/10.1007/s00330-013-2770-9

91. Barendregt AM, Mazzoli V, van den Berg JM et al (2019) T1 $\rho-$ mapping for assessing knee joint cartilage in children with juvenile idiopathic arthritis - feasibility and repeatability. Pediatr Radiol. https://doi.org/10.1007/s00247-019-04557-4

92. Hemke R, Nusman CM, van den Berg JM et al (2017) Construct validity of pixel-by-pixel DCEMRI:Correlation with conventional MRI scores in juvenile idiopathic arthritis. Eur J Radiol 94:1-5. https://doi.org/10.1016/j.ejrad.2017.07.003

93. Barendregt AM, van Gulik EC, Lavini C et al (2017) Diffusionweighted imaging for assessment of synovial inflammation in juvenile idiopathic arthritis: a promising imaging biomarker as an alternative to gadolinium-based contrast agents. Eur Radiol 27:4889 4899. https://doi.org/10.1007/s00330-017-4876-y

94. Nusman CM, Hemke R, Lavini C et al (2017) Dynamic contrastenhanced magnetic resonance imaging can play a role in predicting flare in juvenile idiopathic arthritis. Eur J Radiol 88:77-81. https:// doi.org/10.1016/j.ejrad.2017.01.003

95. Barendregt AM, Nusman CM, Hemke R et al (2015) Feasibility of diffusion-weighted magnetic resonance imaging in patients with juvenile idiopathic arthritis on 1.0-T open-bore MRI. Skeletal Radiol 44:1805-1811. https://doi.org/10.1007/s00256-015-2208-3

96. Hemke R, Lavini C, Nusman CM et al (2014) Pixel-by-pixel analysis of DCE-MRI curve shape patterns in knees of active and inactive juvenile idiopathic arthritis patients. Eur Radiol 24:1686-1693. https://doi.org/10.1007/s00330-014-3168-z

97. Hilbert F, Holl-Wieden A, Sauer A, Köstler H, Neubauer H (2017) Intravoxel incoherent motion magnetic resonance imaging of the knee joint in children with juvenile idiopathic arthritis. Pediatr Radiol 47:681-690. https://doi.org/10.1007/s00247-017-3800-6

Publisher's note Springer Nature remains neutral with regard to jurisdictional claims in published maps and institutional affiliations. 


\section{Affiliations}

Robert Hemke $^{1} \cdot$ Nele Herregods $^{2} \cdot$ Jacob L. Jaremko $^{3} \cdot$ Gunnar Åström $^{4} \cdot$ Derk Avenarius $^{5} \cdot$ Fabio Becce $^{6}$. Dennis K. Bielecki ${ }^{7}$. Mikael Boesen ${ }^{8}$. Danoob Dalili ${ }^{9} \cdot$ Chiara Giraudo $^{10} \cdot$ Kay-Geert Hermann ${ }^{11}$. Paul Humphries ${ }^{12}$. Amanda Isaac ${ }^{13}$ - Anne Grethe Jurik ${ }^{14}$. Andrea S. Klauser ${ }^{15}$. Ola Kvist ${ }^{16} \cdot$ Frederiek Laloo $^{2} \cdot$ Mario Maas $^{1}$. Adam Mester ${ }^{17} \cdot$ Edwin Oei $^{18}$. Amaka C. Offiah ${ }^{19} \cdot$ Patrick Omoumi $^{6} \cdot$ Olympia Papakonstantinou $^{20}$. Athena Plagou $^{21}$. Susan Shelmerdine ${ }^{12}$. Paolo Simoni ${ }^{22} \cdot$ Iwona Sudoł-Szopińska ${ }^{23}$ - Laura Tanturri de Horatio ${ }^{24}$. James Teh $^{25} \cdot$ Lennart Jans ${ }^{2} \cdot$ Karen Rosendahl ${ }^{5}$

1 Department of Radiology and Nuclear Medicine, Amsterdam University Medical Centers, Amsterdam Movement Sciences, Academic Medical Center, University of Amsterdam, Meibergdreef 9, 1105 AZ Amsterdam, The Netherlands

2 Department of Radiology and Medical Imaging, Ghent University Hospital, Ghent, Belgium

3 Department of Radiology and Diagnostic Imaging, Faculty of Medicine and Dentistry, University of Alberta, Edmonton, Canada

4 Department of Radiology, Uppsala University, Uppsala, Sweden

5 Department of Radiology, University Hospital of North Norway, Tromsø, Norway

6 Department of Diagnostic and Interventional Radiology, Lausanne University Hospital, Lausanne, Switzerland

7 Department of Diagnostic Imaging, Kings College Hospital, London, UK

8 Department of Radiology, Bispebjerg and Frederiksberg Hospital, Copenhagen, Denmark

9 Department of Radiology, Chelsea and Westminster Hospital NHS Foundation Trust, London, UK

10 Radiology Institute, Department of Medicine - DIMED, Padova University, Padua, Italy

11 Department of Radiology, University Hospital Charité, Berlin, Germany

12 Department of Radiology, Great Ormond Street Hospital, London, UK

13 Department of Radiology, Guy’s \& St Thomas Hospitals, London, UK
14 Department of Radiology, Aarhus University Hospital, Aarhus, Denmark

15 Department of Radiology, Medical University of Innsbruck, Innsbruck, Austria

16 Department of Paediatric Radiology, Karolinska University Hospital, Stockholm, Sweden

17 Department of Radiology, National Institute of Rheumatology and Physiotherapy, Budapest, Hungary

18 Department of Radiology and Nuclear Medicine, Erasmus University Medical Center (Erasmus MC), Rotterdam, The Netherlands

19 Academic Unit of Child Health, University of Sheffield, Western Bank, Sheffield, UK

20 Department of Radiology, “Attikon" Hospital, National University of Athens, Athens, Greece

21 Private Radiological Institution, Athens, Greece

22 Department of Radiology, Reine Fabiola Children's University Hospital of Bruxelles, University of Bruxelles, Brussels, Belgium

23 Department of Radiology, National Institute of Geriatrics, Rheumatology and Rehabilitation and Department of Medical Imaging, Medical University of Warsaw, Warsaw, Poland

24 Department of Diagnostic Imaging, Bambino Gesù Children's Hospital, Rome, Italy

25 Department of Radiology, Nuffield Orthopaedic Centre, Oxford University Hospitals NHS Trust, Oxford, UK 